\title{
Ergonomics in the psychiatric ward towards workers or patients?
}

\author{
Salerno Silvana ${ }^{\mathrm{a}^{*}}$, Forcella Laura ${ }^{\mathrm{b}}$, Di Fabio Ursula ${ }^{\mathrm{b}}$, Figà Talamanca Irene ${ }^{\mathrm{c}}$, Boscolo Paolo ${ }^{\mathrm{b}}$, \\ ${ }^{a}$ ENEA Casaccia, Division of Biomedicine, SP 018, Rome, Italy \\ ${ }^{\mathrm{b}}$ Occupational Health, University of Chieti \\ ${ }^{c}$ University of Rome, La Sapienza
}

\begin{abstract}
Introduction. Patient's aggressive behavior is one of the major problem in the psychiatric ward. Here we present the preliminary results of a psychiatric ward case-study, of a public hospital in the Chieti province, in order to plan ergonomic improvement. Method We applied the Method of Organizational Congruencies in the psychiatric ward in order to study the relationship between organized hospital work and nurses wellbeing in a 24 hour shifts. Results We observed 58 main phases in the three work shifts. The technical actions are mainly those of any hospital wards (shift briefing, preparing and administering drugs, recording data on clinical charts, etc.). We found important differences mainly due to the nurses overcontrol activities on the patients behavior (preventing suicides or self destructive behavior), the occurrence of restraint procedure towards patients, the pollution due to patient's cigarette smoke. Discussion The fear of patient's self destructive behavior or other aggressive behaviour are the main cognitive and social aspects of this hospital ward. Nurses working in this psychiatric ward have to accept: locked doors, poor and polluted environment, restraint procedure with high risk of aggression and no availability of mental health care programs. A new interdisciplinary concept for ergonomics in psychiatry setting may represent a challenge for both nurses and patients and the community.
\end{abstract}

Keywords: psychiatric ward, ergonomics, health care workers, nurses, aggressions

\section{Introduction}

One of the most neglected dimension of occupational health is mental health at work. Unhealthy mental working conditions may increase mental diseases among workers. The increase use of drugs such as antidepressants, the rate of suicides [1] the suicidal feelings [2] represent only some unreported major events taking place in the work settings. Ergonomics as an interdisciplinary science should have a global view of the relations between physical, mental and social health as a modern challenge in planning the care. Hospital work has been studied by different ergonomic perspectives although cognitive and social ergonomics is still poorly investigated with some relevant exceptions [3]. This is probably due to the fact that mental health of both patients and health care workers are not enough considered in hospital cure and care. Mental health status is a priority within psychiatric patients but very often not in health care workers dealing with them. The italian architect Renzo Piano planned an ergonomic concept for a new general hospital considering "Humanity" at the top of all hospital outcomes [4]. Unfortunately "humanity" is still a challenge to achieve in many public or private caring or curing places. This is also due to the fact that elderly people with minor psychiatric symptoms are often left in "caring" homes without cure. Psychiatric patients in hospital wards can face the same conditions. The issue of mental patients is ethically sensitive. In Italy the human rights of psychiatric patients were only recognized after the so called "antipsychiatric reform" in 1978. Earlier psychiatric patients were victims of violence themselves and suffered isolation and neglect. Thus the ethical problem of violence in the mental health setting is still debated, especially in the cases of

*Corresponding author. E-mail: silvana.salerno@enea.it 
forcible hospitalisation and restraint. Ethical and therapeutical balance between psychiatric patients health (their family and community) and health care workers is complex. In a previous study [5] we found how involuntary admission, in the hospital psychiatric ward was the main cause of physical and verbal aggressions towards nurses. Patient's aggressive behavior and coping with this behaviour represents one of the major responsibility in the psychiatric ward. To further explore this phenomenon, we undertook a specific ergonomics study in the psychiatric ward of a public hospital in the Chieti province where the rate of mental diseases is higher, particularly suicide, if compared with national one.

\section{Methods}

The Method of Organizational Congruencies consists (MOC) of the detailed recording of "technical actions" performed by a worker in a typical work day and in each work shift. The following items are recorded in a grid: type of technical action, characteristic of the work including age, gender, whether the action was performed by a single worker or in collaboration with others, instruments and tools used (ex. electrocardiograph), duration of the actions, the location (ex. office, ward, etc.) and the technical knowledge required to perform the action. We applied the MOC [6] in the psychiatric ward (17 beds) of a major public hospital in province of Chieti, part of the Abruzzo region of central Italy, considering the 24-hour nursing cycle. Twenty five health care workers $(5$ physicians and 20 nurses) and 4 auxiliary personnel, more than half are women, are employed in the psychiatric ward. We focused on nurses work, organized in three typical work shift $(7-14 ; 14-21 ; 21-7)$. We selected the main organizational constraints and we discussed the peculiarity of the ergonomics provision in this hospital ward compared to others hospital units. We interviewed all nurses and the head nurse also applying Job Content Questionnaire (JCQ), Goldberg Questionnaire and Maslach Burnout Inventory. We have also integrated our study with the accidents records of the hospital in the period (19982007 ) in order to detect work related accidents in the psychiatry ward. These data will follow as a second step of the research and are not shown.

\section{Results}

We recorded observations of the work of one nurse in each of the three shifts for a total of 24 hours. This yielded a total of 58 main technical actions in the three shifts 19 morning, 21 afternoon, 18 night. (Table 1) whose Organizational Constraints are shown in Table 2. The intensity of work measured by the number of actions per hour performed to carry out the activities is three main phases/hour. Technical actions performed are similar to other hospital wards (shift briefing, preparing and administering drugs, recording data on clinical charts, cleaning the patients, etc.) [7] with some important differences due to the forcible treatment such as restraint and control of patient's behaviour and belongings. Nurses working in psychiatric ward have to excercise a high control on the patients behaviour to prevent suicides or self destructive behaviour but also to prevent aggressions towards them or any other patients. Restraint procedure towards patients in this hospital setting is not an exception. In fact we observed three patient's restraint actions in 24 hours concerning two men and one woman. The Psychiatric Unit is located at the third floor (despite the national rules on a groundfloor location to prevent suicide). The psychiatric ward environment is almost empty: only beds, no colors, naked walls, windows and main door closed for patient's safety (each nurse has a a set of nine keys) [8]. At the reception patients are forced to give any personal belonging to the nurses (also the cigarette lighter) that keep any kind of materials in specific locked boxes. In any time nurses can body search patients to prevent dangerous actions with any kind of object. The prohibition to get a cigarette lighter and the smoking prohibition during night shift are frequent cause of "escalation" in the communication [9] with a high risk of aggression. Patients are allowed to smoke in the ward during morning and afternoon shifts despite the national law against cigarette smoking in workplaces because the rate of psychiatric inpatients smokers is very high [10]. In order to reduce the ward smoking pollution nurses mantain one main bars window open facing a cold microclimate during winter. Nurses are also forced to work one double shift per month (10-15 hours) increasing their work load. Nurses have a yearly perdiodical medical examination only related to biological risks because of possible contact with HIV and HIC positive drug addictive patients. No nurses' mental health is examined periodically or after major aggressive events. 
Table 1

Main technical actions in a 24 hours shift

\begin{tabular}{|c|c|c|c|c|}
\hline Main technical actions & $\begin{array}{c}\text { Day } \\
7-14 \\
\text { (N. 19) }\end{array}$ & $\begin{array}{c}\text { Afternoon } \\
14-21 \\
\text { (N. 21) }\end{array}$ & $\begin{array}{c}\text { Night } \\
21-7 \\
\text { (N. 18) }\end{array}$ & $\begin{array}{c}\text { Total } \\
24 \text { hours } \\
\text { (N. 58) }\end{array}$ \\
\hline Shift briefing & 2 & 2 & 2 & 6 \\
\hline Putting on uniform & 2 & 2 & 2 & 6 \\
\hline Changing gloves & 2 & 1 & & 3 \\
\hline Medical examinations & 1 & & & 1 \\
\hline Performing electrocardiogram & & 1 & & 1 \\
\hline Preparing and administering drugs & 1 & 2 & 4 & 7 \\
\hline Restraint procedure & 1 & 1 & 1 & 3 \\
\hline $\begin{array}{l}\text { Patient's asking for } \\
\text { (cigarettes, telephone, drugs) }\end{array}$ & 1 & 1 & 3 & 5 \\
\hline Preparing and distributing foods & 1 & 1 & & 2 \\
\hline Cleaning the food trolley & 1 & 1 & & 2 \\
\hline Cleaning the patients & 1 & 1 & & 2 \\
\hline Open the locked door & 1 & 1 & & 2 \\
\hline Lifting the patients & 3 & 3 & & 6 \\
\hline Helping patients to eat & 1 & 2 & & 3 \\
\hline Walking outsidewith patients & 1 & 1 & & 2 \\
\hline Managing patient anxiety & & & 1 & 1 \\
\hline Preparing trolley of day drugs & & & 1 & 1 \\
\hline Others & & 1 & 4 & 4 \\
\hline Total & 19 & 21 & 18 & 58 \\
\hline
\end{tabular}

Table II

Main Organisational Constraints in the Psychiatric ward

\begin{tabular}{|c|c|}
\hline ORGANISATIONAL CONSTRAINTS & $\begin{array}{c}\% \text { of tecnical actions } \\
\text { (N. } 58)\end{array}$ \\
\hline Shift work & 100 \\
\hline Working one extra shift per month & 100 \\
\hline Responsibility for patient's self destructive behaviour & 100 \\
\hline Door and windows locked & 100 \\
\hline Standing position & 95 \\
\hline Smoking pollution in the ward (day-afternoon shifts) & 66 \\
\hline Working with no medical supervision & 66 \\
\hline Direct relations with psychiatric patients (direct care) & 57 \\
\hline No specific training on psychiatric patients & 57 \\
\hline Monotony and repetition of simple action & 31 \\
\hline Risk of "escalation" in the communication towards aggression & 9 \\
\hline Restraint treatment due to aggressive behaviour & 5 \\
\hline
\end{tabular}




\section{Discussion}

The fear of patient's self destructive behaviour or aggressive behaviour towards others are the main cognitive and social aspects of this specific hospital work. Nurses working in this psychiatric ward have to deal with: locked, poor and polluted environment and an unusual gender balanced staff. Hospital management considers gender balance staff as a safety measure, particularly during the night shift, due to men's strenghtful muscular capability to cope with aggressive behaviour, but no scientific data support this organizational choice [11]. No mental health care programmes are available for nursing staff, not even after major aggressive events. In 2003 a male patient committed suicide and the three nurses witnesses left the psychiatric ward facing long lasting psychological impairment. This tendency of nurses to move to other departments or to other professions, causing a shortage of nursing staff in the psychiatric wards has been denounced. The atlas of nurses in mental health confirmed that "the stigma of mental illness, the working conditions, and the lack of incentives for providing mental health care make the recruitment of nurses for mental health more difficult" and that nursing shortage is also due to " the lack of safety and security in the work environment [12]. Nurses staff try to better cope with Organizational Constraints thanks to the "revolving door readmission" phenomenon that reduces the probability of unpredicatble behaviour among patients. This phenomenon is also due to the fact that the hospital is located in a small rural community [13]. The lack of any reward (moral and/or monetary) for nurses effort in facing such working conditions is a European well known studied condition and Italy does not represent an exception [14].

Our results show that how the psychiatric ward observed, and probably many others around the world, are unbalanced and both patients and nurses are forced to face unhealthy conditions. Nurses are exposed to risk for their mental health but also for their physical health such as the shown case of passive smoke. We have also to consider that nurses, and medical doctors, are much more smokers compared with italian population.

In our second step study, with all the collected research materials, together with psychiatric staff we shall try to elaborate a new concept for the psychiatric settings starting from the "humanity" of ergonomics. This concept really needs an interdisciplinary contribution that can help both patients and health care workers without ignoring the difficulties. Experiences such as a violence prevention program in hospital work but also in the local community can be the first future challenge [15].

\section{Acknowledgements}

Thanks all the Psychiatric Unit both nurses, doctors and patients. We are grateful to the Nurse Coordinator of the Unit for his help in collecting data.

\section{References}

[1] Cohidon C., Santin G, Geoffroy-Perez B., Imbernon E. Suicide et activité professionelle en France. Revue d'Epidemiologie et de Santé Publique. 2010 Apr; 58 (2): 139-50

[2] Asberg M. Suicidal feelings and work environment in psychiatric nursing personnel. Soc Psychiatr Epidemiol 1997; 32: 391397

[3] Estryn-Behar M., Kaminski M., Peigne E., Bonnet N., Vaichere E., Golzan C., Azoulay S. Stress at work and mental health status among female hospitla workers. British Journal of Industrial Medicine

[4] Baglioni A, Capolongo S. Ergonomics in planning and reconstruction. G Ital Med Lav Ergon. 2002 Oct-Dec;24(4):405-9

[5] Salerno S., Dimitri L., Figa' Talamanca I. Occupational Risk due to violence in the Psychiatric Ward J. Occup Health 2009: 51: 349-354 1990, 4, 20-28.

[6] Grieco A. et al. 1991. The Method of Organizational Congruencies in a Research Programme on hospital work. In: Proceedings of the $11^{\text {th }}$ Congress of the International Ergonomics Association (Edited by Y. Quéinnec and F. Daniellou) vol. 2 12601261. Ed. Taylor \& Francis, London

[7] Estryn-Behar, Henri Poinsignon. Travailler à l'hopital. ANACT. Assistence Publique Hopiteaux de Paris. Berger Levrault Paris, 1989

[8] Van Der Merwe M0 Locked doors: a survey of patients, staff and visitors. J Psychiatr Ment Health Nurs. 2010 Dec;17(10):873-80

[9] Paul Watzlawick; Janet Beavin Bavelas; Don D Jackson. Pragmatics of humancommunication; a study of interactional patterns, pathologies, and paradoxes New York, Norton [1967]

[10] Aubin HJ. Management of smoking cessation in patients with psychiatric disorders. Curr Med Res Opin. 2009 Feb;25(2):511-8

[11] Messing K, Silverstein BA.Gender and occupational health. Scand J Work Environ Health. 2009 Mar;35(2):81-3. Epub 2009 Apr 1.

[12]www.who.int/mental_health/evidence/nursing_atlas_2007. pdf

[13] No authors. Reducing revolving door readmissions. Am Nurse. 2011 May-Jun;43(3)

[14] Li J, Galatsch M, Siegrist J, Müller BH, Hasselhorn HM; 5 Reward frustration at work and intention to leave the nursing profession--prospective results from the European longitudinal NEXT study. European NEXT Study group. Int J Nurs Stud. 2011 May;48(5):628-35

[15] Magnavita Nicola Violence Prevention in a small-scale psychitric Unit. Program planning and evaluation. Int. J. Occup. Environ. Health $2011 ; 17: 345-353$ in press. 